
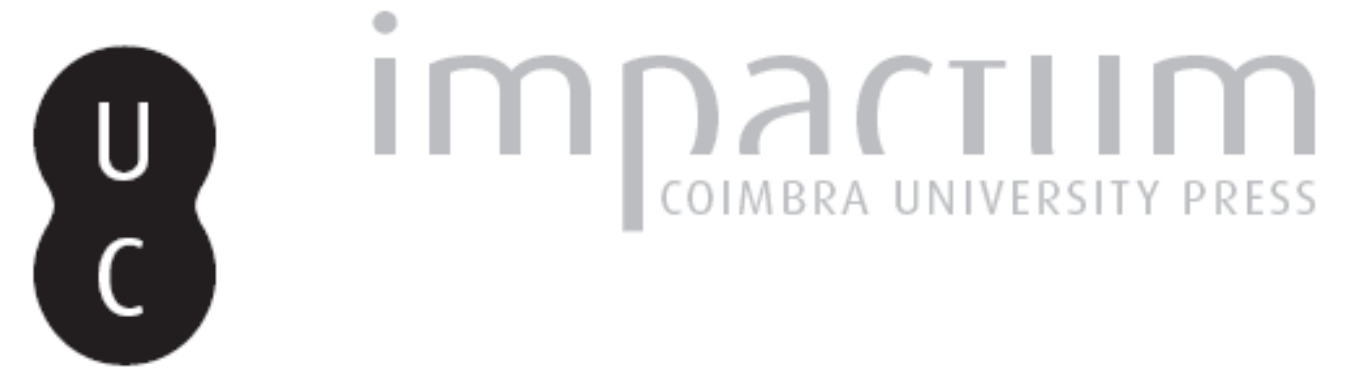

\title{
Programas y processos sobre la docencia del proyecto y la arquitectura
}

\section{Autor(es): Domingo Santos, Juan}

Publicado por: Editorial do Departamento de Arquitetura

URL persistente:

URI:http://hdl.handle.net/10316.2/37260

DOI:

DOI:http://dx.doi.org/10.14195/1647-8681_4_10

Accessed : $\quad$ 26-Apr-2023 05:20:46

A navegação consulta e descarregamento dos títulos inseridos nas Bibliotecas Digitais UC Digitalis, UC Pombalina e UC Impactum, pressupõem a aceitação plena e sem reservas dos Termos e Condições de Uso destas Bibliotecas Digitais, disponíveis em https://digitalis.uc.pt/pt-pt/termos.

Conforme exposto nos referidos Termos e Condições de Uso, o descarregamento de títulos de acesso restrito requer uma licença válida de autorização devendo o utilizador aceder ao(s) documento(s) a partir de um endereço de IP da instituição detentora da supramencionada licença.

Ao utilizador é apenas permitido o descarregamento para uso pessoal, pelo que o emprego do(s) título(s) descarregado(s) para outro fim, designadamente comercial, carece de autorização do respetivo autor ou editor da obra.

Na medida em que todas as obras da UC Digitalis se encontram protegidas pelo Código do Direito de Autor e Direitos Conexos e demais legislação aplicável, toda a cópia, parcial ou total, deste documento, nos casos em que é legalmente admitida, deverá conter ou fazer-se acompanhar por este aviso.

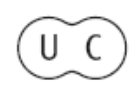




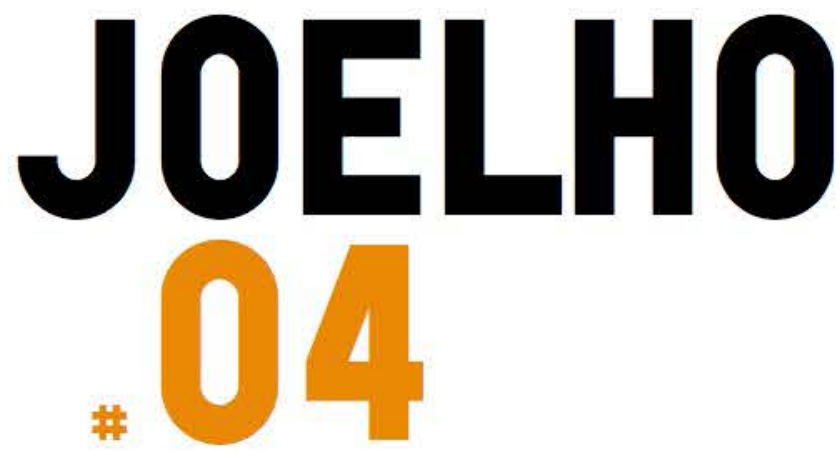

\section{ENSINAR PELO PROJETO \\ TEACHING THROUGH DESIGN}

\section{Coordenaçẫo:}

Paulo Providência

Gonçalo Canto Moniz

Alexandre Alves Costa Juan Domingo Santos Florian Beigel Philip Christou Elizabeth Hatz David Leatherbarrow Andrew Clancy Colm Moore Michael McGarry Willemijn Wilms Floet

Exposição TAPE 20Ir-12 


\section{Juan Domingo Santos}

Programas y procesos

Sobre la docencia del proyecto

y la arcuitectura
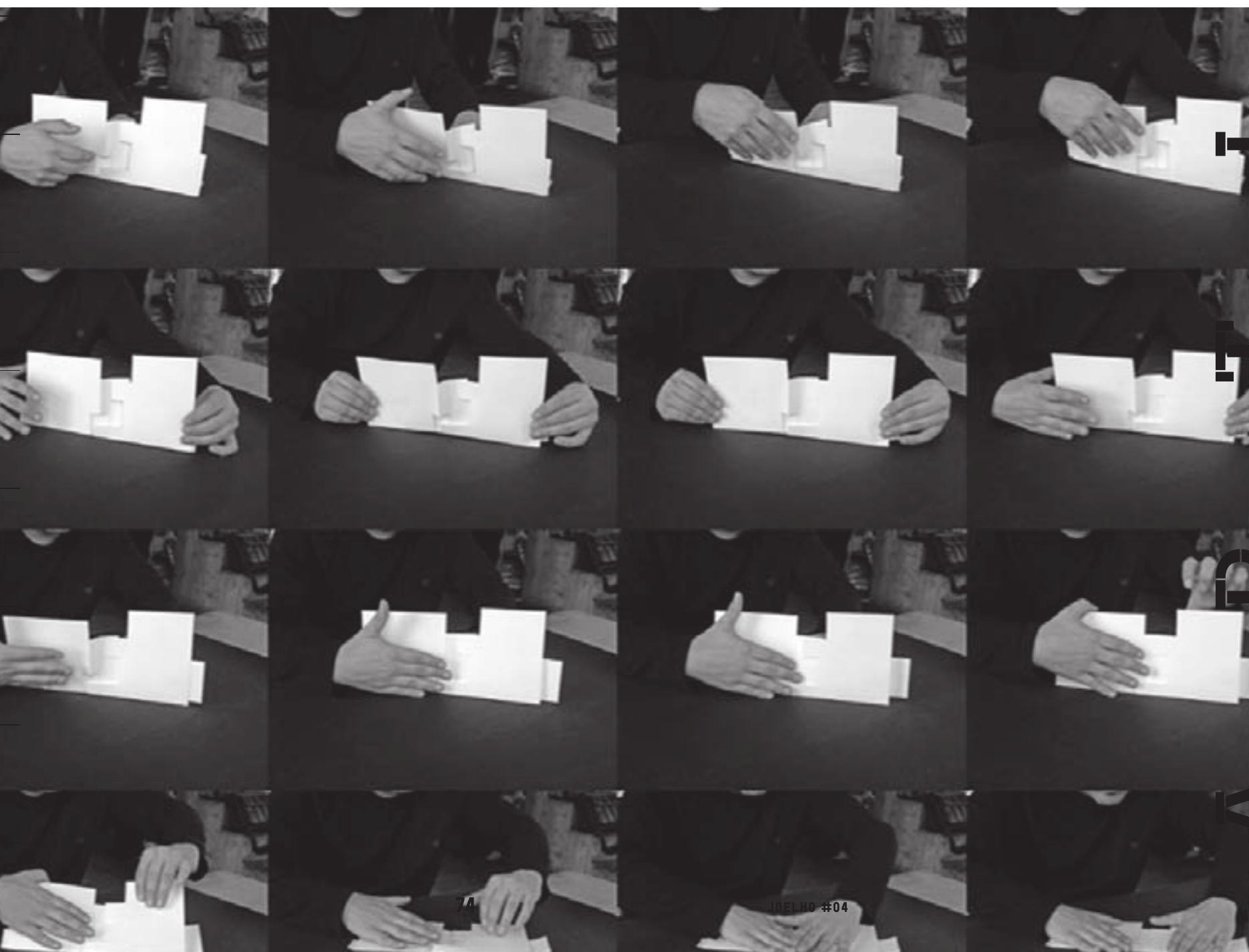
El escultor Richard Serra pronunció una enigmática frase en una entrevista que llamó poderosamente mi atención por lo provocador de sus palabras. La frase en cuestión decía: “Uso es abuso. Sobre el inquietante juego de la subversión”, en alusión al sentido final de la obra de arte y como crítica al funcionalismo que acompaña a la creación a lo largo de la historia. El rotundo comentario deja en entredicho a la función como el fin último de una creación, poniendo en crisis la relación directa y exclusiva entre ambas. Para Serra pensar en la función representa abusar del significado de una obra, sin duda más amplio que la mera funcionalidad a la que quedaría reducida. De hecho, como aclara más tarde el artista en la entrevista, lo que realmente le interesa al abordar un trabajo no es tanto la función en si con la que se concibe la obra como el juego subversivo que hacemos de la misma.

Esta crítica a la función como el fin último y exclusivo de la creación, es sin duda también una dura crítica a la disciplina arquitectónica y al modo de hacer de los arquitectos, que defienden la forma de sus edificios como el resultado del desarrollo de una función específica. La arquitectura, sin embargo, es una actividad vital más amplia, con una fuerte condición humana que aúna experiencia, emoción y uso. Experiencia en cuanto que implica experimentar con la vida y las cosas. Emoción como la capacidad inherente de toda arquitectura para hacernos sentir y emocionarnos, y el uso, en cuanto que desarrollo de las actividades del hombre. Tres aspectos siempre presentes en las arquitecturas que despiertan nuestro interés. Uno de los objetivos para un arquitecto debería ser hacer emocionante la vida, y para que se produzcan las emociones en el simple estar y vivir, sacar a la luz en sus construcciones valores que cualifiquen la forma de habitar. El problema comienza cuando la arquitectura se asocia exclusivamente al programa y se independiza de la experiencia y de la emoción. Muchas de las construcciones que nos rodean son abordadas sólo desde la funcionalidad, dejando de lado cuestiones vitales para el hombre.

La arquitectura no se reduce al dibujo ni a la función, no es un plano ni una fotografía. En un proyecto hay encuentros fortuitos, coincidencias, hallazgos, y también relaciones que se entretejen las unas con las otras y que acaban por convertirse en el destino del trabajo. Desde esta perspectiva, lo que llamamos creación de la obra de arquitectura no es más que una acción basada en observar, prestar atención de manera receptiva a cuanto sucede en nuestro entorno y establecer relaciones entre elementos aparentemente inconexos (fig.1)

El proyecto es un campo de exploración abierto que nos permite ir y venir entre cosas diversas con mínima energía. Pienso que en la mayoría de las ocasiones la arquitectura no surge en el taller de trabajo y es consecuencia de la acción de buscar y juntar. En los proyectos existen siempre objetos robados, piezas sin valor original que son trasladadas de lugar y de tiempo. Para nuestro asombro todo está
1. Ilusiones urbanas. Casa para un mago. La idea de una "arquitectura Braille" en la ciudad está tomada de la actividad del mago al manipular con sus manos los naipes de la baraja. 


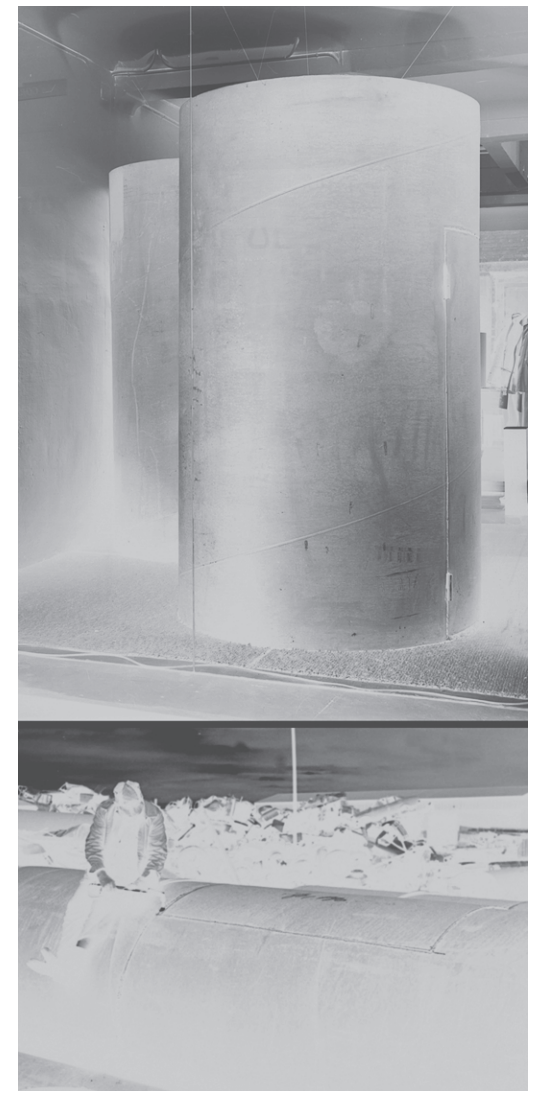

2. Probadores de ropa. Tuberías de acero cortén encontradas en una chatarrería.

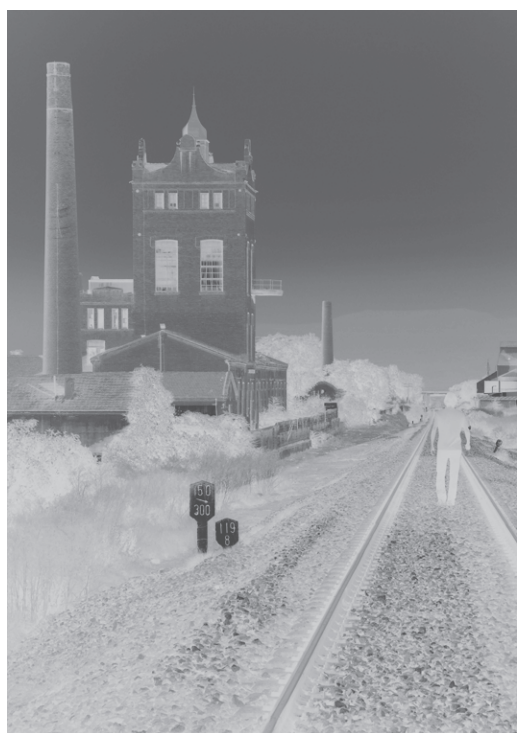

3. Torre alcoholera rehabilitada como estudio de arquitectura desde 1986. Fábrica de azúcar San Isidro en la vega de Granada. más próximo de lo que en principio podríamos imaginar, de manera que es posible alcanzar una cierta continuidad entre todo lo que nos rodea, sólo hace falta tiempo para lograr el equilibrio.

Desde este punto de vista, un programa podría consistir en fabricar una experiencia para registrar las posibilidades de un lugar, establecer un censo de sensibilidades del territorio y sus habitantes. El proyecto podría comenzar por pasear e inventariar de forma minuciosa toda una serie de experiencias personales sobre lo cotidiano. Pasear para experimentar y fabricar mapas de acontecimientos cargados de vida, una manera simultánea de lectura y escritura de la ciudad. Me gusta pasear con mis estudiantes, convertirnos en viajeros expoliadores y recolectores de objetos en un intento de aproximación a una realidad compleja a través de la experiencia personal de cada uno de nosotros. La finalidad es obtener una visión conjunta como resultado de todas nuestras visiones sobre el "As found", lo encontrado o hallado en el paseo como forma de conocimiento de un territorio y su capacidad de transformación. Caminar entre tiempo y espacios, reconocer trazas, preexistencias, restos abandonados y dinámicas de ocupación. No existen los desiertos. Se trata de una técnica libre de reconocimiento de un lugar y sus posibilidades que nos permite construir mapas de elementos que identificamos con actividades. Sin duda la arquitectura está hecha de historias de encuentros diversos, acontecimientos donde reconocer al ser humano (fig.2)

Hace tiempo decidí adentrarme en una antigua fábrica de azúcar en la vega de Granada e instalar allí mi taller de arquitectura en un antiguo torreón de ladrillo en medio del campo agrícola. La intención desde el principio fue conocer aquel extraño lugar en abandono a través de mis propias experiencias. Me gustaba la manera nada ortodoxa de descubrir el ámbito. Un espacio que desentrañaba a saltos, sin orden preestablecido y con libertad plena, como sucede cuando haces un proyecto y avanzas sin saber hacia donde se dirige, hasta que un día decides detenerte y recomponer toda la experiencia vivida y rememorar el proceso con ese espíritu de aventura con el que comenzó la historia. Años más tarde, el 16 de abril de 2000, escribí en un cuaderno el sentimiento de felicidad que me invadía cada vez que me adentraba en el recinto. Desde entonces este antiguo espacio industrial se ha convertido en un laboratorio libre para el ensayo e investigación de sus posibilidades. Durante este tiempo he realizado paseos al azar por el inmenso recinto, he trasladado objetos de lugar que encontraba a mi paso, he organizado actividades en los espacios interiores de las naves abandonadas con intención de descubrir hasta qué punto dan de si. Me acostumbré a vivir sin reloj y medía el paso del tiempo según el tipo de tren y el sentido en que circulaba al pasar junto a la torre. Todas las experiencias me aportaron una valiosa información sobre el lugar que fueron trasladadas más tarde a un mapa relacional de usos y tiempos, ofreciendo una visión del lugar y sus expectativas (fig.3, 4). En el año 2008, el director de cine Juan 
Bollaín rodó el documental "Un encuentro" que describe mis paseos y descubrimientos en la fábrica así como las experiencias llevadas a cabo en ella hasta hoy (www.juandomingosantos.com)

Creo que la arquitectura no está hecha de ideas preconcebidas, proviene de la experimentación con temas muy diversos asociados a cuestiones de paisaje, arqueología, agricultura, producción y patrimonio, entre otras, y el proyecto es un juego que acaba por disolver las formas habituales del espacio en un intento por humanizarlo. Lo que entendemos por programa no es más que una relación específica de la arquitectura con cada uno de estos aspectos.

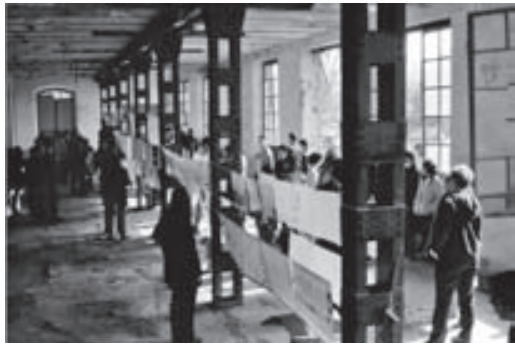

4. Exposición de trabajos en el interior de una de las naves industriales. Fábrica de azúcar San Isidro, Granada

\section{Bibliographical References}

Trillo de Leyva, J.L. (2001) Argumentos. Sobre la contigüidad en arquitectura, Serie Arquitectura $n^{\circ} 19$,

Universidad de Sevilla, Sevilla.

-

Domingo Santos, J., Montaner, J.M. (2009)

Experiencias 2, Colección Experiencias del

Máster Laboratorio de la Vivienda del Siglo XXI,

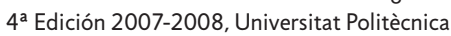

de Catalunya y la School of Pofessional \&

Executive Development, Barcelona.

Sebald, W.G. (2001) Austerlitz, Anagrama, Barcelona. 